BMJ Open

Sport \&

Exercise

Medicine

\section{Attitudes, beliefs and factors influencing football coaches' adherence to the $11+$ injury prevention programme}

To cite: Shamlaye J, Tomšovský L, Fulcher ML. Attitudes, beliefs and factors influencing football coaches' adherence to the $11+$ injury prevention programme. BMJ Open Sport \& Exercise Medicine 2020;0:e000830. doi:10.1136/ bmjsem-2020-000830

Accepted 6 September 2020

Check for updates

(C) Author(s) (or their employer(s)) 2020. Re-use permitted under CC BY-NC. No commercial re-use. See rights and permissions. Published by BMJ.

For numbered affiliations see end of article.

Correspondence to Julie Shamlaye; j.shamlaye@axissportsmedicine. co.nz

\section{ABSTRACT}

Objective To explore football coaches' beliefs and attitudes about injury prevention and the 11+ injury prevention programme, and to investigate factors that may influence adherence to the $11+$ injury prevention programme. Methods A total of 538 football coaches who had completed an injury prevention education workshop were invited to participate in a web-based nationwide survey. The survey questions explored beliefs and attitudes about injury prevention and the 11+ injury prevention programme, self-reported adherence to the $11+$ programme, as well as perceived barriers and facilitators to the use of the 11+ programme. Results There were 158 respondents. The majority believe that injury prevention is part of their coaching role (94\%) that a structured warm-up is an important part of their team's preparation for training and games (96\%), and that the $11+$ is effective (92\%). While most respondents (95\%) use the $11+$, modifications are common. Participants with greater coaching experience are more likely to use the programme. Time constraints are the main barriers to adherence, while knowing that the programme enhances performance is seen as a major facilitator.

Conclusions Coaches who attended an injury prevention workshop have positive attitudes towards injury prevention and the 11+ programme. However, coaches with less coaching experience may be less likely to use the 11+ and could therefore be the target population for future education workshops. Promoting the performance enhancing effects of the $11+$ and encouraging modifications could improve acceptability and adherence.

\section{INTRODUCTION}

Football (soccer) is the most popular sport in the world, with the number of participants globally estimated to be more than 265 million. ${ }^{1}$ It is estimated that, on average, a player has two injuries per year. ${ }^{2}$ This means that there are likely to be more than 500 million footballrelated injuries each year. Aside from the direct financial burden associated with the diagnosis and treatment of these injuries, additional negative consequences exist. ${ }^{3}$ These include time away from school or work, potential loss of sporting opportunities and the possible longterm physical consequences of injuries, for example, osteoarthritis after anterior cruciate ligament rupture. ${ }^{45}$

What are the new findings?
The injury prevention benefits of the $11+$ are well
understood by football coaches.
Coaches with less coaching experience may be less
likely to use the $11+$.
Adherence could be improved by encouraging
modifications, promoting the performance
enhancing effects and targeting coaches with less
coaching experience.

There has been an increasing interest in strategies that might reduce the risk of injury. ${ }^{6}$ One of these is the $11+$ injury prevention programme. This programme was developed to replace a 'traditional' warm-up and was designed specifically to reduce the incidence of football injuries. The preventive and performance enhancing effects of the programme have since been evaluated in multiple publications. ${ }^{6-12}$ When done regularly, the $11+$ has been shown to reduce the incidence of all injuries by $39 \%$, and is effective in both men's and women's football. ${ }^{69}{ }^{10}$ It has also been shown to be an effective warm-up and to improve individual measures of sporting performance. ${ }^{11-13}$ While the $11+$ programme appears to be highly effective in a research setting, its uptake has been relatively limited in a real-world setting. ${ }^{14}{ }^{15}$ It has been well established that adherence with the programme correlates with the reduction in injury risk. ${ }^{6}{ }^{12} \mathrm{~A}$ lack of adherence is therefore a major impediment to the effectiveness of this type of programme and further injury prevention research is warranted to identify determinants of adherence. ${ }^{16}$

Coaches play an essential role in the implementation of injury prevention strategies. Unfortunately, efforts to engage with coaches and to include an injury prevention programme into mandatory coach education have not been entirely successful in optimising adherence. ${ }^{17}$ Despite efforts to enhance coaches' knowledge, attitudes and intent to 
use an injury prevention programme, adherence can remain unsatisfactory. ${ }^{18}$ Existing data have shown that coaches who perceive injury prevention programmes to be too time-consuming or not football-specific enough are less likely to be compliant. ${ }^{19}$ It has also been suggested that coaches with greater football playing experience are less likely to implement the programme. ${ }^{20}$

Since 2015 New Zealand Football (NZF), in partnership with New Zealand's national insurance company, the Accident Compensation Corporation (ACC), has conducted a nationwide roll-out of the 11+ injury prevention programme. Part of this unique initiative has involved running injury prevention workshops for coaches, including how to administer the warm-up, and integrating the $11+$ into the NZF coaching curriculum. This has been facilitated by the appointment of an Injury Prevention Specialist to each of the seven regional federations and involved a combination of lecture-style content and a practical session where the coach participated in the 11+. The collaboration has also led to the development of similar warm-up programmes for other sporting codes that are responsible for the majority of sports-related injury claims and associated costs in New Zealand. ${ }^{21}$ The aim of the current study was to investigate factors that may influence adherence to the $11+$ injury prevention programme by surveying coaches who have participated in these workshops.

\section{METHODS}

\section{Participants}

Coaches who completed an NZF injury prevention workshop $(\mathrm{n}=538)$ were invited to participate. These coaches were sent an email invitation via NZF to participate in a secure, web-based survey. A second invitation was sent a month later. Ethical approval was obtained through the University of Auckland Human Participants Ethics Committee (Ref. 018493).

\section{Survey/procedures}

Participants completed a web-based survey via a secure online platform. The survey instrument was based on a survey used by other researchers. ${ }^{20}$ It was modified and shortened, excluding questions about participants' knowledge of football injuries, their coaching and first aid qualifications, and history of injuries among their players and immediate family, in an attempt to increase its relevance and maximise response rate. The final survey contained 15 questions. These enquired about basic participant demographics, football coaching and playing experience, attitudes and beliefs around injury prevention, adherence to the $11+$ and perceived barriers to adherence. The survey contained a combination of multiple-choice questions and 5-point Likert scales. It took approximately $10 \mathrm{~min}$ to complete.

\section{Data analysis}

All the data were downloaded and exported into a Microsoft Excel spreadsheet. Before statistical analysis, the data were cleaned and edited. The frequency distribution of responses was summarised to each question on the survey. Responses based on the 5-point Likert scales ('strongly disagree', 'disagree', 'neutral', 'agree', 'strongly agree') were collapsed into the 3-point Likert scales ('strongly disagree' / 'disagree', 'neutral', 'strongly agree'/'agree'). Contingency tables with the frequency distribution of responses were produced for each nominal variable of interest: (i) age of coaches (15-19 years, 20-29 years, $30-39$ years, $40-49$ years, $50-59$ years, and aged over 60 years); (ii) gender (male, female, gender diverse); (iii) years of coaching experience (first season, 1-2 years, 3-5 years, $6-10$ years, greater than 10 years); (iv) level at which a coach has worked (professional, semi-professional, senior, youth, junior); (v) playing experience of coaches ('never played football', 'first season playing football', 'only played football as a child or adolescent', 'played football as an adult'); (vi) level at which a coach has played (professional, semi-professional, senior, youth, junior, 'never played football before'); and (vii) history of an significant sports injury keeping a coach from playing for more than 4 weeks ('yes', 'no', 'not sure'). Fisher's exact tests were used to determine any possible associations for each contingency table. All statistical analyses were performed using MATLAB version R2018b (The MathWorks, Inc., Natick, Massachusetts, USA) and statistical significance was defined as $\mathrm{p}<0.05$. Cramér's $\mathrm{V}$ was used to measure the strength of all associations that were found significant.

\section{Patient and public involvement}

This research was done without public involvement. Public were not invited to comment on the study design, interpret the results, or contribute to the writing or editing of this document for readability or accuracy.

\section{RESULTS}

\section{Participants}

The response rate was 29\% (158/538). The participants were classified into age groups, with the youngest between 15 and 19 years and the oldest over 60 years. The majority of respondents were male $(n=136,86 \%)$ and were between 30 and 59 years $(n=127,80 \%)$. Most of the coaches $(84 \%)$ had more than 2 years of coaching experience, with $34 \%$ of total respondents having more than 10 years of coaching experience. A total of 18 coaches $(11 \%)$ had coached at professional or semi-professional level. Most of the respondents $(\mathrm{n}=149,94 \%)$ had some experience playing football.

\section{Beliefs and attitudes about the 11+ programme}

Participants' beliefs and attitudes towards injury prevention and the $11+$ injury prevention programme are shown in figure 1 . The majority $(n=151,96 \%)$ agreed or strongly agreed that a structured warm-up is an important part of preparing their team for both training and games. The level of agreement increased with the coaches' years of 
Some football injuries can be prevented

Injury prevention is part of my role as a coach

In my role as a coach, I can help reduce a player's risk of injury

A structured warm-up is an important part of preparing my team for training and games

The 11+ programme can reduce injuries among players

I can include the $11+$ programme into each team training session

I can include the $11+$ programme prior to each game

I would enjoy including the 11+ programme into each training session and prior to each game
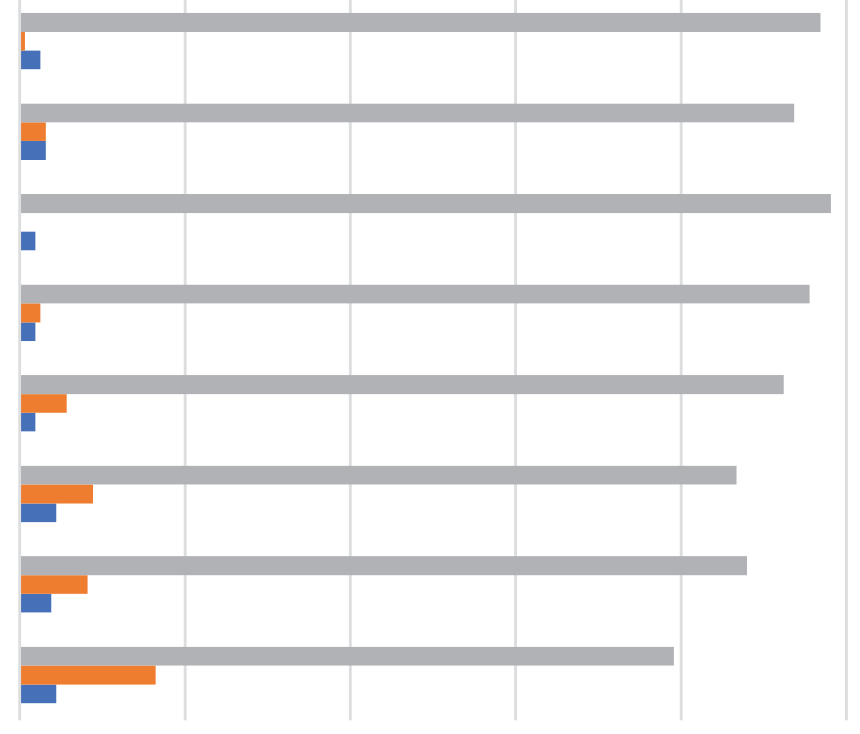

0 20 40 60 80

Percentage

Figure 1 Respondents' beliefs and attitudes about injury prevention and the 11+ programme.

playing experience $(\mathrm{p}=0.0008$, Cramer's $\mathrm{V}=0.2462)$ and level of playing experience $(\mathrm{p}=0.006$, Cramer's $\mathrm{V}=0.2585)$. Most respondents $(\mathrm{n}=146,92 \%)$ believed that the $11+$ programme can reduce injuries among players. Those who had longer experience playing football were more likely to agree with this statement $(\mathrm{p}=0.0019$, Cramer's V=0.2369).

The reported use of the $11+$ programme is shown in figure 2. Overall, $79 \%(n=125)$ of respondents said that they enjoy using the $11+$ programme. The majority $(n=85$, $57 \%$ ) reported making modifications to the programme and using the programme at least twice per week $(n=118$, $79 \%$ ). The older the coach, the more strongly they felt able to include the $11+$ programme into each training session ( $p=0.025$, Cramer's V=0.2068). Confidence with delivering the $11+$ programme also increased with increasing age of the coach $(\mathrm{p}=0.04$, Cramer's V=0.2494).

The lower the level at which the coaches had played, the more likely they were to agree with the statement that they can include the $11+$ programme into each team training session $(p=0.01$, Cramer's $V=0.2255)$. The higher the level the coaches had played, the more likely they were to report that they would enjoy it $(p=0.002$, Cramer's $\mathrm{V}=0.2814$ ). Coaches with higher levels of coaching experience were also more likely to report using the programme in some way ( $\mathrm{p}=0.005$, Cramer's $\mathrm{V}=0.2894$ ). Respondents with longer coaching careers reported using the programme more often than those with less experience $(p=0.003$, Cramer's V=0.2565). In contrast, the higher the level at which the respondent had coached, the less likely they felt able to use the $11+$ prior to each competitive game ( $\mathrm{p}=0.003$, Cramer's $\mathrm{V}=0.2583)$.

\section{Barriers and facilitators}

The most commonly reported barrier to adherence was not having enough time $(n=64,40 \%)$. Figure 3 outlines the full list of perceived barriers to adherence to the $11+$ injury prevention programme. Knowing the programme enhances performance was the most commonly reported facilitator ( $76 \%$ of respondents). Figure 4 outlines the other perceived facilitators to improve adherence to the $11+$ injury prevention programme.

\section{DISCUSSION}

It is widely accepted among clinicians and researchers that coaches play a crucial role in the implementation of injury prevention programmes. ${ }^{19} 22-25$ The current study demonstrates that the coaches themselves also believe that they are important in injury prevention work and believe that they can influence injury risk among their players. The majority of coaches in this study believe that some injuries are preventable and that the $11+$ is an effective tool for helping prevent injury, reflecting the strong research-based evidence that supports the use of the $11+.{ }^{6}$ From a practical perspective, this may also mean that NZF's coach education programmes have been effective. The findings of the current study will likely help direct future injury prevention efforts at NZF. It appears that there is a need to focus more clearly on developing strategies to foster the implementation of this type of programme rather than continued provision of education about the potential benefits of the programme.

In the current study, coaches who have experience coaching at higher levels feel less able to include the programme prior to each match, possibly reflecting the 
Do you use the $11+$ programme?

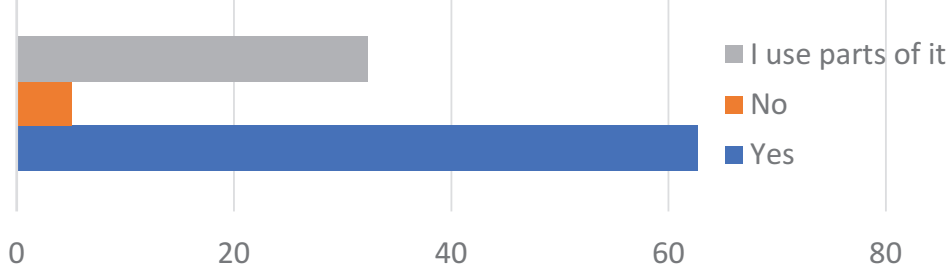

If you use the 11+ programme, have you made any modifications to it?

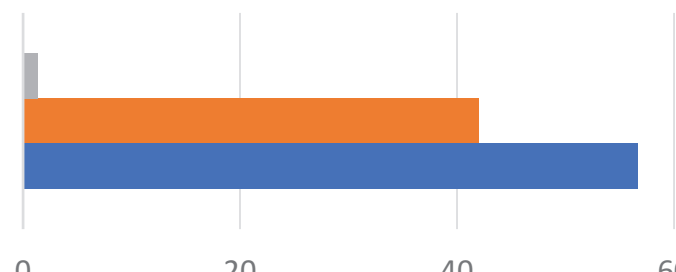

- I don't know

No

- Yes

80

100
On average, how many times a week does your team complete this warm-up programme?

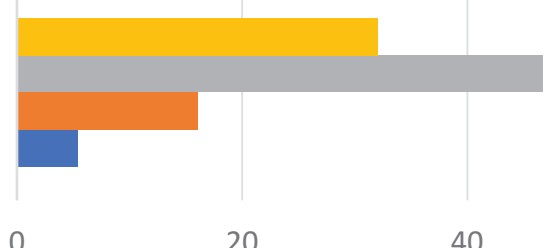

20
40

Percentage
3 times or more

Twice

- Once

- Less than once a week

80

100

Figure 2 Reported use of the 11+ injury prevention programme.

challenges of game day logistics at more competitive levels. However, despite this lower commitment to game day use of the $11+$, those with greater coaching experience report better adherence to the programme, or its parts, and are more likely to use the $11+$ at the recommended frequency of two or more times per week. This supports the findings of a previous study which found an association between longer duration of coaching experience and successful implementation of an injury prevention programme. ${ }^{26}$ In the current study, there is no difference in the reported use of the 11+ among coaches of varying playing experience, however, a difference in attitudes about the 11+ exists. Coaches who have played at higher levels feel less able to include the programme into every training session (than those with less playing experience), despite being more likely to report enjoying the programme. These findings suggest that there may be a discrepancy between the perceived importance and enjoyment of a programme and the practicalities of using it. This is consistent with existing data relating to coach playing experience, ${ }^{20}$ and studies that have shown that validated injury prevention programmes are not widely done at the elite level. ${ }^{142728}$ These differences in attitudes found in the current study suggest that focusing on education of coaches with more playing experience, as well as those with less coaching experience, could be beneficial as a future strategy. Given that these coaches appear enthusiastic about injury prevention, future research may be able to define and address some of these logistical or practical considerations.

Multiple potential barriers to adherence have previously been identified through survey-based research on professional team coaches, athletes and their support staff, with some related to the content of the 11+ programme and others to the delivery and support of the programme. ${ }^{29} 30$ The current study has highlighted time constraints ('not having enough time' and 'the warm-up is too long') and having no ball involved as the most commonly reported barriers to adherence. The issue of limited time is not unique to football and the $11+$ 


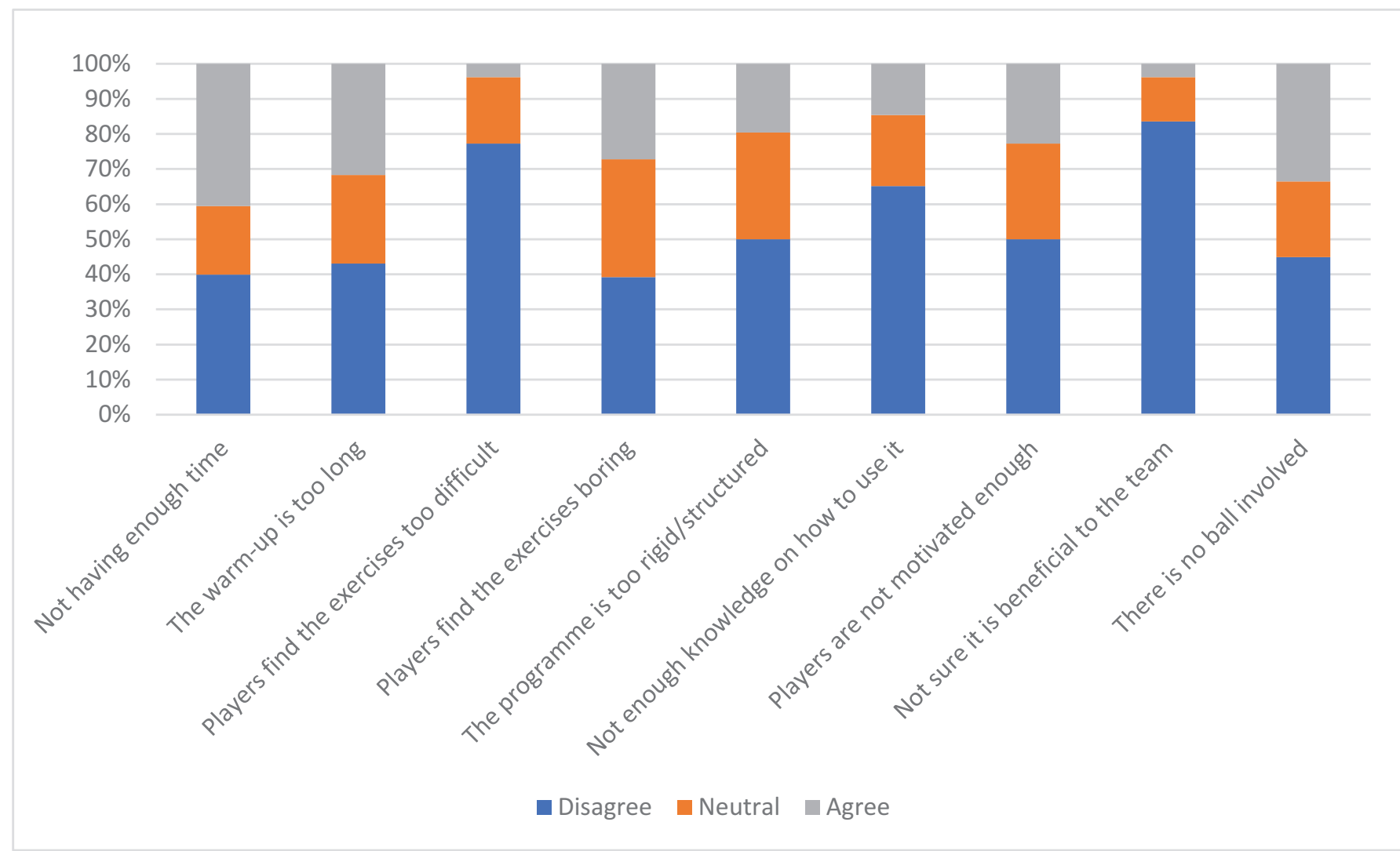

Figure 3 Perceived barriers to adherence to the 11+ programme.

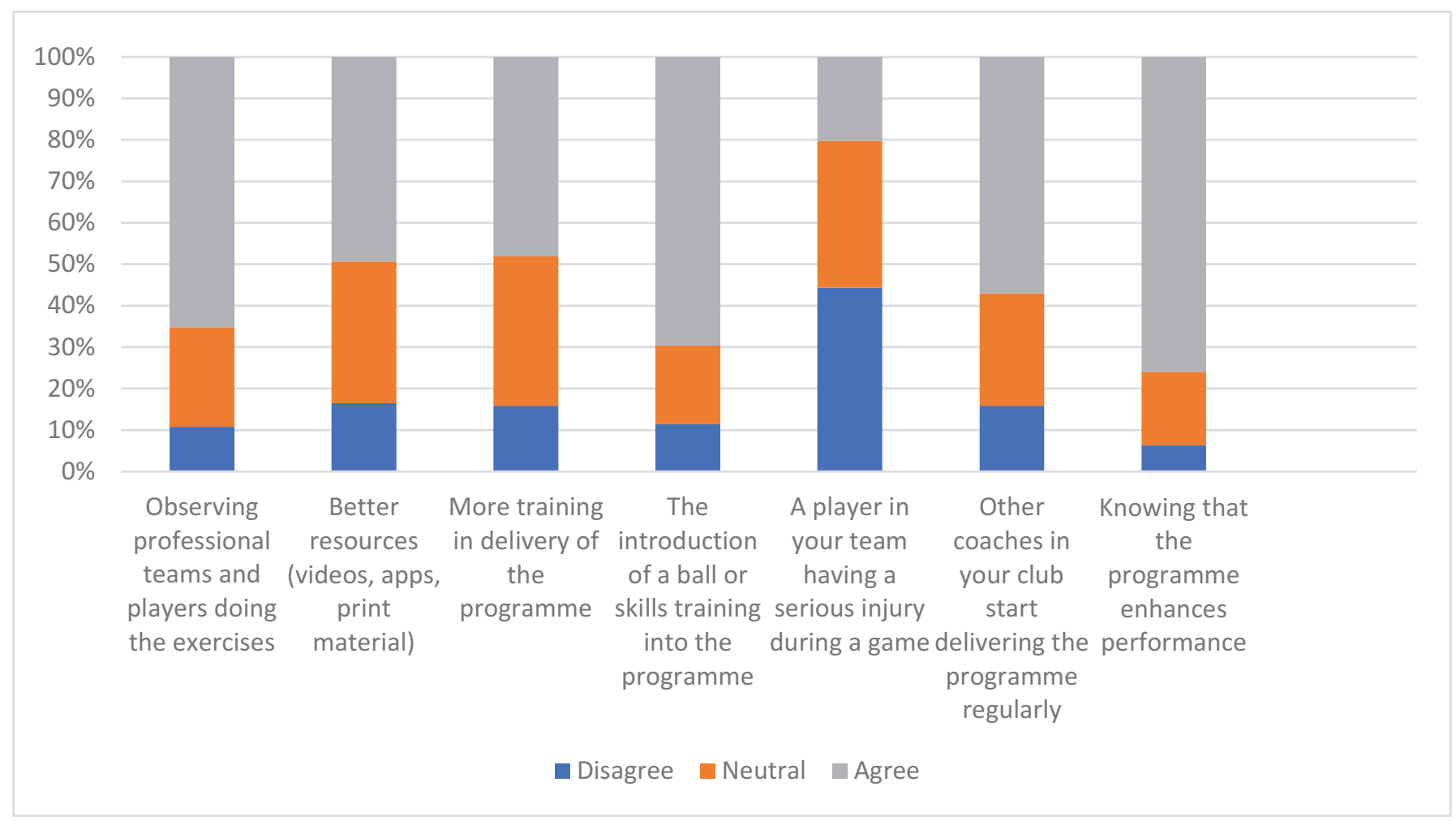

Figure 4 Perceived facilitators in improving adherence to the 11+ programme. 
programme (which takes 20 min to complete). ${ }^{31} 32$ Based on these findings, working to shorten the programme or to better integrate the individual elements into a training session may be an important consideration in the development of future strategies to foster adherence. While shortening the programme may improve adherence, coaches at the professional youth football level consider 10-25 min to be an appropriate amount of time spent on a pre-training warm-up. ${ }^{14}$ It is therefore possible that at more competitive levels time is not perceived to be a barrier, but rather the content of the programme. In addition, influencing behaviour change at professional level may be more challenging. Other authors have identified that at elite level, despite adequate theoretical knowledge about appropriate injury prevention exercises, the daily use of these exercises remains lower than expected, and suggest that teams at this level have a tendency to resist the adoption of new strategies that deviate from traditional or well-established practices. ${ }^{28}$ These theories may also help to explain the differences in attitudes found in the current study around use of the 11+ among those with experience playing at higher levels, as previously discussed. This indicates a need to cater an injury prevention programme to the needs of the individual team. In keeping with the coaches' positive attitudes and beliefs about the programme, a lack of perceived benefit was also not generally thought to be a problem. Neither was not having enough knowledge on how to use the programme, unlike the findings of other recent research where a lack of 11+ knowledge among coaches was considered to be an important barrier to its implementation. ${ }^{33} 34$ This suggests that less time and energy need to be invested in demonstrating the importance of the programme to coaches, and more focus can be placed on developing the content of the programme itself as well as developing effective implementation strategies.

While the overall reported use of the $11+$ exercises is high compared with previous surveys, ${ }^{14}{ }^{33}$ the use of modifications appears to be common practice, with less than half of users implementing the programme in its original form. This high reported use of modifications is in keeping with the findings of other researchers, ${ }^{33}$ and there appears to be a desire among end-users to make changes or improvements to the 11+ programme. Making modifications to the 11+ programme to address identified barriers, such as the addition of a ball, may be a strategy that could help improve adherence. While it is becoming increasingly accepted that allowing flexibility and tailoring of a programme may be necessary to improve acceptability among various groups and settings, ${ }^{21} 2931$ there could be an associated reduction in the injury prevention benefits. ${ }^{22}$ It has been suggested that the greater the number of exercises adhered to in the $11+$ programme, the more effective it is. ${ }^{23}$ While making changes to the programme may compromise its overall efficacy, it is likely that doing even a single exercise would confer some benefit. A clear example of this would be the use of the Nordic hamstring exercise (a component of the 11+), which has been well validated for the prevention of hamstring injuries. ${ }^{35}$ Furthermore, there is evidence to suggest that changing the order of the $11+$ components, by completing the strength, plyometric and balance exercises at the end of training, may actually improve (not compromise) adherence as well as effectiveness of the programme. ${ }^{36}$ Finally, there is also evidence that doing the programme infrequently can still provide some benefit. ${ }^{19}$ Based on the widespread use of modifications among our study's participants it appears that strict adherence to a programme may well be unrealistic in a real-world setting. Given that coaches appear inclined to modify the programme, and given that there is data to suggest that this does not entirely compromise the programme's efficacy, perhaps this should be encouraged and researched further.

Knowledge that the 11+ programme enhances performance is seen as important for facilitating its use. This finding is consistent with existing research. ${ }^{26}$ The introduction of a ball and skills training, knowing that other coaches in the same club use the programme and having more training and resources are also reported as factors that would encourage adherence. Again other studies have identified similar facilitators. ${ }^{22}{ }^{32}$ In addition, coaches in this study believe that seeing professional players and teams do the exercises would encourage adherence to the programme. This is also in keeping with previous studies where it was identified that high profile athletes and the media were influential. ${ }^{19}$ Future educational programmes could therefore aim to improve the awareness about the performance enhancing effects of the 11+ and further strategies should continue to engage the media and involve well-known athletes in the promotion of the programme. Considering coaches', players' as well as other stakeholders' perceptions and opinions in the development of future injury prevention strategies would also likely be valuable and can improve uptake and adherence. ${ }^{24} 37$

This study adds to a relatively limited pool of data regarding adherence to injury prevention programmes. As a nationwide study involving football coaches at all levels of competition, its generalisability is a strength. A limitation of the current study is the relatively poor response rate. The risk of selection bias is also high as participants self-selected by both choosing to attend the initial workshop and then by completing the survey. This may mean that coaches who were more invested in injury prevention were more likely to be included, and that the current study overestimates the level of understanding and interest in the programme. The addition of a question in the survey asking participants to describe what modifications they made to the programme would have been of added value. Including a matched cohort of coaches who have not attended the workshop would have allowed comparisons to be made between those who have and those who have not been exposed to this educational platform. Finally, quantitative methodology has limitations and a qualitative study would likely be a better way of more fully evaluating coach beliefs and could be a useful next step. 


\section{CONCLUSION}

The majority of coaches who attended an injury prevention education workshop and have participated in this study have continued to use some of the components of the $11+$ programme and appear to have positive attitudes and beliefs towards injury prevention and the programme itself. This study has highlighted several possible avenues to improve adherence. Shortening the warm-up and introducing a ball may be useful. Promotion of the programme by professional teams and players and a focus on the programme's performance enhancing effects are also likely to improve uptake. A target population for future workshops could be those with less coaching experience, as these coaches may be less likely to use the programme.

\author{
Author affiliations \\ ${ }^{1}$ Axis Sports Medicine Specialists, Auckland, New Zealand \\ ${ }^{2}$ Auckland University of Technology (AUT), Sports Performance Research Institute, \\ Auckland, New Zealand \\ ${ }^{3}$ Auckland University of Technology (AUT), School of Sport and Recreation, Auckland, \\ New Zealand \\ ${ }^{4}$ New Zealand Football, Auckland, New Zealand
}

Acknowledgements We would like to acknowledge the support of New Zealand Football and their assistance with this research.

Contributors JS and MLF contributed to the study conception and design. Material preparation and data collection were performed by JS and analysis was performed by LT. The first draft of the manuscript was written by JS and all authors commented on previous versions of the manuscript. All authors read and approved the final manuscript.

Funding This research did not receive grants from any funding agency in the public, commercial or not-for-profit sectors

Competing interests MLF is employed by New Zealand Football and is a member of the FIFA Medical Committee.

Patient consent for publication Written consent was not required, as advised by the University of Auckland Human Participants Ethics Committee, because the web-based survey was anonymous. Written participant information stated that completion of the survey would be taken as consent to participate.

Ethics approval The web-based survey and methodology of this study was approved by the University of Auckland Human Participants Ethics Committee (Ref. 018493).

Provenance and peer review Not commissioned; externally peer reviewed.

Data availability statement The data that support the findings of this study are available from the corresponding author, JS, upon reasonable request.

Open access This is an open access article distributed in accordance with the Creative Commons Attribution Non Commercial (CC BY-NC 4.0) license, which permits others to distribute, remix, adapt, build upon this work non-commercially, and license their derivative works on different terms, provided the original work is properly cited, appropriate credit is given, any changes made indicated, and the use is non-commercial. See: http://creativecommons.org/licenses/by-nc/4.0/.

ORCID iD

Julie Shamlaye http://orcid.org/0000-0002-1566-9968

\section{REFERENCES}

1 FIFA. FIFA big count 2006: 270 million people active in football. 2007. Available https://www.fifa.com/mm/document/fifafacts/bcoffsurv/big count.statspackage_7024.pdf

2 Peterson L, Junge A, Chomiak J, et al. Incidence of football injuries and complaints groups., in different age groups and skill-level. Am J Sport Med 2000;28:S51-7.

3 Statistics on our claims. Available https://www.acc.co.nz/about-us /statistics/\#injury-stats-nav (accessed 25 Apr 2018)

4 Von Porat A, Roos EM, Roos H. High prevalence of osteoarthritis 14 years after an anterior cruciate ligament tear in male soccer players: a study of radiographic and patient relevant outcomes. Ann Rheum Dis 2004;63:269-73.

5 Lohmander LS, Östenberg A, Englund M, et al. High prevalence of knee osteoarthritis, pain, and functional limitations in female soccer players twelve years after anterior cruciate ligament injury. Arthritis Rheum 2004;50:3145-52.

6 Thorborg K, Krommes KK, Esteve E, et al. Effect of specific exercisebased football injury prevention programmes on the overall injury rate in football: a systematic review and meta-analysis of the FIFA 11 and 11+ programmes. Br J Sports Med 2017;51:562-71.

7 Mccall A, Davison M, Andersen TE, et al. Injury prevention strategies at the FIFA 2014 World Cup: perceptions and practices of the physicians from the 32 participating national teams. $\mathrm{Br} J$ Sports Med 2015;49:603-8.

8 Sadigursky D, Braid JA, De Lira DNL, et al. The FIFA 11+ injury prevention program for soccer players: a systematic review. BMC Sports Sci Med Rehabil 2017;9:1-8.

9 Silvers-Granelli H, Mandelbaum B, Adeniji O. Efficacy of the FIFA 11+ injury prevention program in the collegiate male soccer player. Am $J$ Sport Med 2015;43:2628-37.

10 Soligard T, Myklebust G, Steffen K, et al. Comprehensive warm-up programme to prevent injuries in young female footballers: cluster randomised controlled trial. BMJ 2009;338:95-9.

11 Reis I, Rebelo A, Krustrup P, et al. Performance enhancement effects of federation internationale de football association's 'the 11+' injury prevention training program in youth futsal players. Clin J Sport Med 2013;23:318-20.

12 Meeuwisse WH, Bizzini M, Emery CA, et al. High adherence to a neuromuscular injury prevention programme (FIFA 11+) improves functional balance and reduces injury risk in Canadian youth female football players: a cluster randomised trial. $\mathrm{Br} J$ Sports Med 2013;47:794-802

13 Impellizzeri FM, Bizzini M, Dvorak J, et al. Physiological and performance responses to the FIFA 11+ (part 2): a randomised controlled trial on the training effects. J Sports Sci 2013;31:1491-502.

14 O'Brien JO, Finch CF. Injury prevention exercise programmes in professional youth soccer: understanding the perceptions of programme deliverers. BMJ Open Sport Exerc Med 2016;2:e000075.

15 Bizzini M, Dvorak J. FIFA 11+: an effective programme to prevent football injuries in various player groups worldwide - a narrative review. Br J Sports Med 2015;49:59.

16 Owoeye OBA, Mckay CD, Verhagen EALM, et al. Advancing adherence research in sport injury prevention. 2018;2017-8.

17 Junge A, Lamprecht M, Stamm H, et al. Countrywide campaign to prevent soccer injuries in Swiss amateur players. Am J Sport Med 2010;1-7.

18 Frank BS, Register-Mihalik J, Padua DA. High levels of coach intent to integrate a ACL injury prevention program into training does not translate to effective implementation. J Sci Med Sport 2015;18:400-6.

19 Soligard T, Nilstad A, Steffen K, et al. Compliance with a comprehensive warm-up programme to prevent injuries in youth football compliance with a comprehensive warm-up programme to prevent injuries in youth football. Br J Sports Med 2010;44:787-93.

20 Mckay CD, Steffen K, Romiti M, et al. The effect of coach and player injury knowledge, attitudes and beliefs on adherence to the FIFA 11+ programme in female youth soccer. Br J Sports Med 2014;48:1281-6.

21 Fulcher ML, Carlson I, Mitchell C, et al. Development and implementation of the ACC sportsmart warm-up programme: a nationwide sports injury prevention initiative in New Zealand. $\mathrm{Br}$ J Sports Med 2018;52:1334-8.

22 Lindblom H, Carlfyord S, Hagglund M. Adoption and use of an injury prevention exercise program in female football : a qualitative study among coaches. Scand J Med Sci Sports 2018;28:1295-303.

23 Steffen K, Meeuwisse WH, Romiti M, et al. Evaluation of how different implementation strategies of an injury prevention programme (FIFA 11+) impact team adherence and injury risk in Canadian female youth football players: a cluster-randomised trial. Br J Sports Med 2013;47:480-7

24 Donaldson A, Lloyd DG, Gabbe BJ, et al. We have the programme, what next? Planning the implementation of an injury prevention programme. Inj Prev 2017;23:273-80.

25 Bizzini M, Junge A, Dvorak J. Implementation of the FIFA 11+ football warm up program: how to approach and convince the football associations to invest in prevention. Br J Sports Med 2013;1-4.

26 Joy EA, Taylor JR, Novak MA, et al. Factors influencing the implementation of anterior cruciate ligament injury prevention strategies by girls soccer coaches. J Strength Cond Res 2013;27:2263-9.

27 Mccall A, Dupont G, Ekstrand J. Injury prevention strategies, coach compliance and player adherence of 33 of the UEFA elite club injury 
study teams: a survey of teams' head medical officers. Br J Sports Med 2016;50:725-30.

28 Loose O, Achenbach L, Fellner B, et al. Injury prevention and return to play strategies in elite football: no consent between players and team coaches. Arch Orthop Trauma Surg 2018;138:985-92.

29 O'Brien J, Finch C. The implementation of musculoskeletal injury-prevention exercise programmes in team ball sports: a systematic review employing the RE-AIM framework. Sport Med 2014;44:1305-18.

30 O'Brien JO, Finch CF. Injury prevention exercise programs for professional soccer : understanding the perceptions of the end-users. Clin J Sport Med 2017;27:1-9.

31 Richmond SA, Donaldson A, Macpherson A, et al. Facilitators and barriers to the implementation of iSPRINT: a sport injury prevention program in junior high schools. Clin J Sport Med 2020;30:231-8.

32 Saunders N, Otago L, Romiti M, et al. Coaches perspectives on implementing an evidence-informed injury prevention programme in junior community netball. Br J Sports Med 2010;44:1128-32.
33 Donaldson A, Callaghan A, Bizzini M, et al. Awareness and use of the 11 + injury prevention program among coaches of adolescent female football teams. Int J Sports Sci Coach 2018;1-10.

34 Donaldson A, Callaghan A, Bizzini M, et al. A concept mapping approach to identifying the barriers to implementing an evidence-based sports injury prevention programme. Inj Prev 2019;25:244-51.

35 van der Horst N, Smits DW, Petersen J, et al. The preventive effect of the Nordic hamstring exercise on hamstring injuries in amateur soccer players: a randomized controlled trial. Am J Sport Med 2015;43:1316-23.

36 Whalan M, Lovell R, Steele JR, et al. Rescheduling part 2 of the 11+ reduces injury burden and increases compliance in semi-professional football. Scand J Med Sci Sports 2019;1-11.

37 Ageberg E, Bunke S, Lucander K, et al. Facilitators to support the implementation of injury prevention training in youth handball: a concept mapping approach. Scand J Med Sci Sport 2019;29:275-85. 